\section{UNA NUEVA ETAPA}

\section{A NEW ERA}

\section{Joaquín Poch Broto}

Presidente de la Real Academia Nacional de Medicina de España
Se inicia con este número de Anales de la Real Academia Nacional de Medicina una nueva etapa, con el objetivo de aprovechar el potencial de las tecnologías de la información y la comunicación para convertir una revista centenaria en un instrumento moderno para la difusión del conocimiento médico, con mayor alcance y utilidad para los lectores.

La publicación en línea de nuestra revista permite no solo mayor inmediatez, sino también una ampliación del espacio y la representación iconográfica, que considero de la mayor relevancia.

Por otra parte, este período que iniciamos hoy nos permite adaptarnos a las reglamentaciones habituales de las revistas más modernas. Los Anales y los artículos que contienen cuentan con la acreditación de CrossRef para generar códigos DOI, requisito básico hoy día para las referencias bibliográficas y la multidifusión de contenidos científicos.

Los Anales de la Real Academia Nacional de Medicina de España reafirman sus valores tradicionales de rigor y excelencia, y seguirán siendo espejo de la actividad académica ordinaria con la publicación, en forma de artículos científicos, de las comunicaciones presentadas en la Real Academia durante sus sesiones de los martes. Al ser estas de carácter pluridisciplinar, darán como resultado una revista generalista que, gracias a su divulgación en la red, podrá también ser consultada por los especialistas de cualquier área, merced a su indexación en plataformas como Medline y PubMed, así como en el IME - Índice Médico Español-y en Google Académico.

La publicación en línea permitirá, además, incorporar en sus suplementos monográficos el contenido de las sesiones académicas extraordinarias que reflejan con frecuencia áreas de interés estratégico de la propia Academia.

En fases sucesivas, tenemos la intención de abrir los Anales a autores ajenos a la Real Academia Nacional de Medicina que deseen publicar con nosotros, ya sean artículos de revisión, para lo que nuestra revista ofrece un buen nicho, o bien artículos originales. El sistema de revisión por pares garantizará que los criterios de calidad se puedan seguir manteniendo como en la actualidad.

Aunque nuestra Academia siempre se ha preocupado por la excelencia del lenguaje médico en español, y este seguirá siendo el idioma predominante de los Anales, no podemos ignorar, sin embargo, que el inglés es la lengua franca en las comunicaciones científicas, por lo que Anales aceptará y publicará artículos en dicha lengua.

Espero que este período permita que los Anales de la Real Academia Nacional de Medicina de España sean un vehículo de difusión de la mejor medicina, y que el formato digital se adapte mejor y con más agilidad a un tiempo de transformaciones permanentes. La buena acogida de esta nueva forma de publicación por parte de la Junta de Gobierno es un estímulo de gran importancia para el camino que hoy comenzamos.

No puedo concluir sin manifestar mi agradecimiento al profesor Luis Pablo Rodríguez, que, como Secretario de la Corporación, ha venido editando Anales con dedicación y entrega en los últimos seis años, así como al profesor Eduardo Díaz-Rubio, director científico, y a la profesora Ana María Villegas, redactora jefe de Anales, gracias a los cuales se hace posible esta nueva etapa. 